\title{
Precipitation estimation and nowcasting at IMGW-PIB (SEiNO system)
}

\author{
Jan Szturc, Anna Jurczyk, Katarzyna Ośródka, Andrzej Wyszogrodzki, Mateusz Giszterowicz \\ Institute of Meteorology and Water Management - National Research Institute, Podleśna 61, 01-673 Warsaw, Poland, \\ e-mail:jan.szturc@imgw.pl
}

\begin{abstract}
A System for the Estimation and Nowcasting of Precipitation (SEiNO) is being developed at the Institute of Meteorology and Water Management - National Research Institute. Its aim is to provide the national meteorological and hydrological service with comprehensive operational tools for real-time high-resolution analyses and forecasts of precipitation fields. The system consists of numerical models for: (i) precipitation field analysis (estimation), (ii) precipitation nowcasting, i.e., extrapolation forecasting for short lead times, (iii) generation of probabilistic nowcasts. The precipitation estimation is performed by the conditional merging of information from telemetric rain gauges, the weather radar network, and the Meteosat satellite, employing quantitative quality information (quality index). Nowcasts are generated by three numerical models, employing various approaches to take account of different aspects of convective phenomena. Probabilistic forecasts are computed based on the investigation of deterministic forecast reliability determined in real time. Some elements of the SEiNO system are still under development and the system will be modernized continuously to reflect the progress in measurement techniques and advanced methods of meteorological data processing.
\end{abstract}

Keywords: precipitation, nowcasting, probabilistic forecasts, precipitation estimation, high-resolution data

Submitted 10 February 2017, revised 30 June 2017, accepted 28 July 2017

\section{Introduction}

A quantitative precipitation estimate (QPE) provides basic information for the modelling of many kinds of hydro-meteorological processes, e.g. as input to rainfallrunoff models for flash flood forecasting. It is assumed that especially in small and urbanized catchments a spatial resolution of all precipitation data: i.e., analyses (QPE) and forecasts, should be at least $1 \mathrm{~km}$ with 5-10 min frequency, or even values of $0,1 \mathrm{~km}$ and $1 \mathrm{~min}$ are suggested as optimum (Ten Veldhuis et al. 2014). In order to meet these requirements, weather radar observations are crucial because of their very high spatial resolution. Additional sources of diverse data, such as telemetric rain gauges and satellite observations, are also included in the QPE. However, the data are characterized by different temporal and spatial error structures. Therefore, a combination of the data should be based on quality information determined quantitatively for each input to take advantage of a particular source of precipitation measurements (Berndt et al. 2014; Szturc et al. 2014).

The next step is precipitation nowcasting, i.e., forecasting with a very short lead time - approximately up to 2 hours - and applying a linear extrapolation approach by means of advection of a precipitation field; as well as this, the field evolution is often taken into consideration. Nowcasting for longer lead times is not reliable because the precipitation field evolution is difficult to predict and the real vector field describing the movement of convective cloud structures is not very stable in time. A brief review of contemporary nowcasting models can be found in, e.g., Mecklenburg et al. (2005) and Pierce et al. (2012). At the Institute of Meteorology and Water Management - National Research Institute (in Polish: Instytut Meteorologii i Gospodarki Wodnej - Państwowy Instytut Badawczy, hereafter: IMGW-PIB) presently two nowcasting systems are implemented in the operational mode: the INCA system developed by the Austrian national meteorological service ZAMG (Haiden et al. 2011; Kann et al. 2012) and the precipitation model SCENE (Storm Cell Evolution and Nowcasting) systems developed at IMGW-PIB. Another nowcasting model, the SNOF (Spectral Nowcasting with Optical Flow), is currently being developed at the IMGW-PIB.

Moreover, in order to improve nowcasting skill, mesoscale numerical weather prediction (NWP) models which deliver forecasts with a longer time horizon are also employed. In Poland the COSMO and AROME models are operated at the IMGW-PIB. The NWP models are successful in providing short- and medium-range mesoscale forecasts at the resolution above $2 \mathrm{~km}$. In the cases of convective phenomena triggered by local atmospheric conditions at a very small spatial scale, the NWP models may not allow for the forecasting of precipitation events with sufficient accuracy in terms of rainfall quantity and 
spatial locality (Silvestro et al. 2015). In the forecasting of small-scale severe events, nowcasting models are successful in terms of their tracking, whereas the NWP forecasts are found useful in supplementing the nowcasts with object evolution, especially for lead times longer than about 2 hours (see Fig. 5) (Golding 1998; Atencia et al. 2010).

The IMGW-PIB, as the Polish national meteorological and hydrological service, operates a number of tools for precipitation data generation, processing, nowcasting and forecasting. All the systems need a common algorithmic and informatics framework for the effective management of precipitation data along the following chain: from quantitative precipitation estimation through nowcasting (forecasting) up to merging with ultra short-term forecasting and the generation of probabilistic forecasts. In order to handle these tasks, the SEiNO system (System of Estimation and Nowcasting of Precipitation, in Polish: System Estymacji i Nowcastingu Opadów) has been designed to introduce improvements in already operational models and sub-systems, as well as to initiate research work on missing modules.

The most significant and innovative characteristic of the system, in comparison with similar systems working operationally in other European national meteorological services, is the utilization of quantitative quality information which propagates from the observations to the final products, such as precipitation estimates and forecasts. The quality information is especially crucial in modules for multi-source data combination and multi-model forecast merging, and also constitutes a basis for the generation of probabilistic forecasts.

This paper is organized as follows. After the introduction in Section 1, the SEiNO system is described generally in Section 2 in terms of its structure and input data. In Section 3, algorithms for multi-source QPE generation are briefly presented. In Section 4, deterministic precipitation nowcasting is described. In Section 5, ultra short-term forecasting from NWP models is described. Post-processing of the nowcasts and forecasts, including their merging and subsequent generation of probabilistic forecasts, are described in Section 6. The last section, Section 7, contains a summary of the paper.

\section{The SEiNO system}

\subsection{Overall description}

The tasks of the estimation and forecasting of precipitation fields with high temporal and spatial resolutions are performed by the SEiNO system, which is being developed and implemented at the IMGW-PIB. The general goal of SEiNO is to generate:
- analyses of precipitation fields based on data from various available measurement systems;

- precipitation nowcasts, combined with the forecasts of the NWP mesoscale models;

- probabilistic forecasts.

Currently, all the precipitation data processed by the system are 10-min accumulations with temporal and spatial resolutions of $10 \mathrm{~min}$ and $1 \mathrm{~km}$, respectively.

Apart from the precipitation input, a basis for all algorithms implemented in the SEiNO system constitutes information about precipitation quality. The quality information is generated at each stage of the data processing in the form of fields of dimensionless quantity named quality index, QI (Einfalt et al. 2010), normalized to the range $[0,1]$. Generally, the methodology of the $Q I$ estimation is not unambiguous as it is difficult to determine all sources of uncertainty and their impact quantitatively, therefore a significant part of the scheme of the $Q I$ determination must be arbitrary. Despite these difficulties, the $Q I$ values make a very convenient and effective quality metric.

The computational domain of the size $900 \mathrm{~km} \times 800 \mathrm{~km}$ in the PUWG 92 coordination system covers the whole of the territory of Poland (Figs. 2 and 3). As the data format for precipitation fields, the HDF5 format has been established with the RainDIM information model based on the ODIM model introduced by the EUMETNET OPERA program for weather radar data (Michelson et al. 2014). Applications of the system have been developed mostly in ANSI C and run on the Linux CentOS 6.5 (64-bit) operational system.

\subsection{Structure of the SEiNO}

The SEiNO is able: (i) to provide high quality input data required for hydrological rainfall-runoff models (Tokarczyk et al. 2016), (ii) to track rapidly changing meteorological phenomena at a small spatial scale (as the forecasting cycle is $10 \mathrm{~min}$ and the spatial resolution is $1 \mathrm{~km}$ ), and (iii) to predict their evolution for longer time periods (the lead time is up to 4 hours). In figure 1 a block diagram of the SEiNO system is depicted.

The SEiNO system includes modules which perform the following tasks:

- RainGRS - quality control, processing of particular precipitation inputs, and generation of multi-source precipitation GRS fields;

- INCA-PL2; SCENE; SNOF - nowcasting of precipitation fields (quantitative precipitation nowcast, QPN);

- MERGE - merging of nowcasts and ultra short-term NWP forecasts (quantitative precipitation forecast, QPF);

- ENSEMBLE, PROB - generation of probabilistic forecasts (probabilistic QPF, PQPF); 


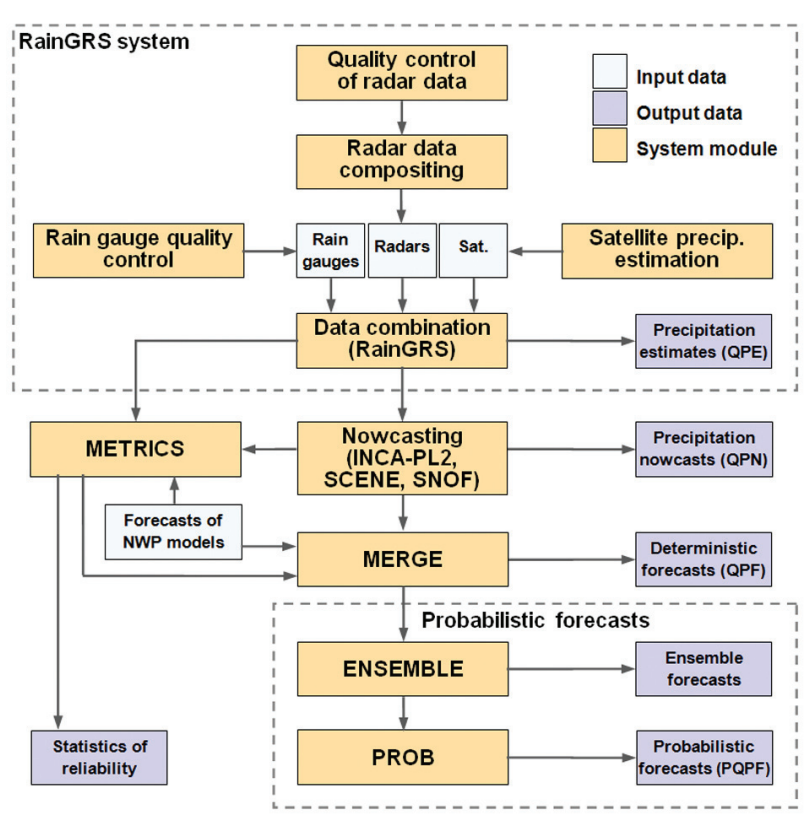

Fig. 1. Simplified scheme of precipitation estimation and nowcasting at IMGW-PIB

- auxiliary tasks: generation of reliability statistics (METRICS), precipitation accumulation (SUM).

Moreover, the system is equipped with a graphical user interface which provides forecasters at IMGW-PIB (meteorologists and hydrologists) with visualizations of the results.

\subsection{Input data}

The SEiNO system processes a variety of precipitation data from the measurement systems described below to employ them in the generation of analyses and forecasts of precipitation fields.

\section{TELEMETRIC RAIN GAUGE NETWORK}

The network consists of 491 gauges (Fig. 2). Each of them is equipped with two sensors: a heated sensor (which works during the winter) and an unheated one. The data are subject to automatic quality control procedures in SEiNO, which mainly consist of: (i) a range check based on climatological values, (ii) analysis of the spatial consistency of gauge data, (ii) analysis of the temporal consistency of the data, and (iv) verification with other measuring techniques, i.e., weather radars and satellite (Szturc et al. 2014). After the quality control, the gauge data are spatially interpolated with the use of the inverse distance weighting technique or a Kriging method to obtain a high-resolution precipitation field. Relevant $Q I$ values for each pixel of a domain are generated from qualities of individual gauge measurements and a factor related to the distance to the nearest gauge.

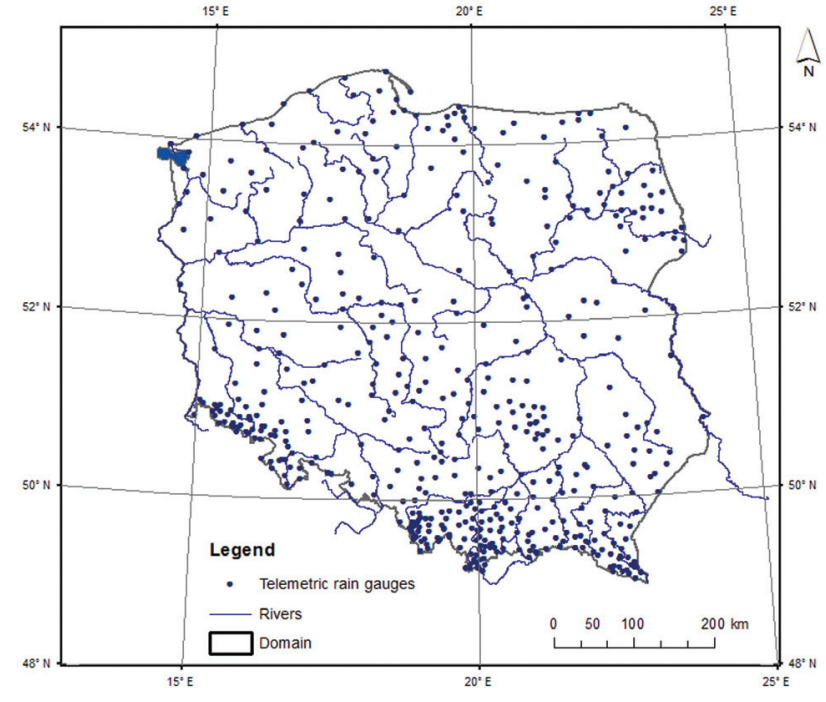

Fig. 2. Deployment of measurement network of telemetric rain gauge stations

\section{POLISH WEATHER RADAR NETWORK POLRAD}

At present the network consists of eight C-band Doppler radars manufactured by Selex ES, including three radars with dual-polarized beam. The POLRAD network covers nearly the whole area of Poland, with a $250-\mathrm{km}$ range of observations. In the south of the domain, the POLRAD data are supplemented with radar data from neighbouring countries: Lithuania (2 radars), Ukraine (1), Slovakia (4), Czech Republic (2), and Germany (3) - all of them are Doppler and dual-polarized (Fig. 3). They significantly improve the range of measurements in this area where, due to mountains, radar beam propagation is limited. The Rainbow system from Selex ES is employed for the data processing.

The weather radar measurements are burdened with many kinds of errors. These can be divided into a few groups (Villarini, Krajewski 2010). The first group is connected with radar beam geometry and includes effects related to the distance from a radar site, like the beam broadening. The next group, which influences the radar estimates in the highest degree in practice, is related to the presence of non-meteorological echoes, mainly caused by ground clutter, external signals from, e.g., RLAN emitters, measurement noise (speckles), and biological echoes from birds or insects. Moreover, errors can be caused by attenuation in heavy rain, anomalous propagation of the radar beam, and beam blockage on terrain which decreases signal strength, as well as by hardware instability. This quality control is performed by the RADVOL-QC system (Ośródka et al. 2014) on 3D raw data (volumes), which also produces $Q I$ fields.

Having the corrected $3 \mathrm{D}$ data, a number of $2 \mathrm{D}$ products may be generated, such as SRI (surface rainfall intensity), i.e., cross section at a constant height above the ground, and then PAC (precipitation accumulation) products can 


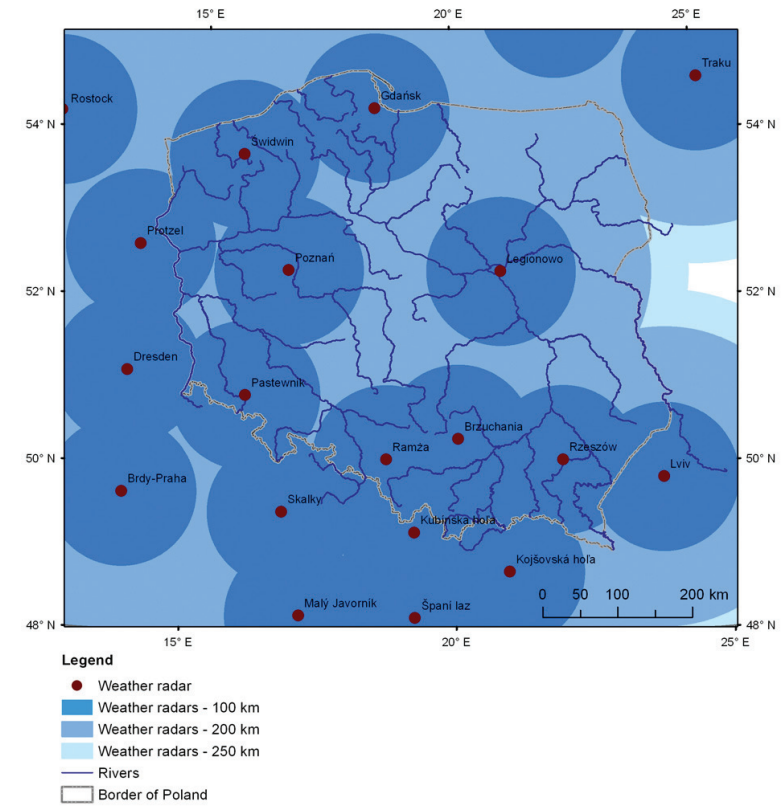

Fig. 3. Deployment of POLRAD weather radar network complemented with radars from neighbouring countries. Radar ranges are marked within a radius of $250 \mathrm{~km}$, the darker colour marks radars with dual polarization of beam

also be generated. The 10-min PAC products from particular radars are merged into composite maps using relevant $Q I$ fields as the criteria.

\section{METEOSAT METEOROLOGICAL SATELLITES}

The data from SEVIRI radiometers on board Meteosats provide information in visible and infrared channels, which is not optimal for precipitation estimation. However, after processing with algorithms from the NWC SAF program, which also employ data from the NWP model, the data constitute a valuable complement to other systems because of their high availability and the fact there are no limitations in spatial range (NWC SAF 2013). For the SEiNO system, a dedicated algorithm for quantitative precipitation estimation which combines several NWC SAF products has been developed (Szturc et al. 2014). Relevant quality fields $Q I$ are also determined by the algorithm. The data are available in a spatial resolution of about $5 \mathrm{~km} \times 6 \mathrm{~km}$, so they are downscaled into $1 \mathrm{~km} \times 1 \mathrm{~km}$ pixels. Their temporal resolution is 5 or 15 min depending on the mode (rapid or standard), thus estimation of 10-min accumulations is necessary.

\section{Estimation of precipitation field (QPE)}

The task of the estimation of precipitation fields on the ground (QPE) as input data for precipitation nowcasting is carried out by the RainGRS module of the SEiNO system. The module merges precipitation data from the measurement techniques listed in Sect. 2.3.
The combination of the multi-source data is based on conditional merging (Sinclair, Pegram 2005), additionally applying information about the data quality. In this approach, the information from a radar is used to obtain the correct spatial structure of the precipitation field, while the field values are fitted to the rain gauge observations. First, spatial interpolation of rain gauge data into the $G_{\text {int }}$ field is performed. Next, uncertainty of the interpolation is assessed from a comparison between the radar field $R$ and the radar field interpolated from data in rain gauge locations $R_{\text {int }}$. Finally, spatially interpolated rain gauge data $G_{\text {int }}$ is corrected by these differences $\left(R-R_{\text {int }}\right)$ to obtain a gauge field modified by radar information $R_{G}$ according to the formula:

$$
R_{G}=G_{\text {int }}+\left(R-R_{\text {int }}\right)
$$

where $G_{i n t}$ is the spatially interpolated rain gauge field; $R$ is the radar precipitation; $R_{\text {int }}$ is the radar precipitation interpolated from data in rain gauge locations.

Subsequently, the resulting precipitation field $R_{G}$ is merged with radar data $R$ to obtain the combined gaugeradar $G R$ field from the formula (Szturc et al. 2014):

$$
G R=\frac{R_{G} \cdot Q I_{G}+R \cdot Q I_{R}}{Q I_{G}+Q I_{R}}
$$

where $Q I_{G}$ and $Q I_{R}$ are the quality indices for gauge and radar, respectively. A combined gauge-satellite field $G S$ is obtained analogically to the above procedure, but the satellite data $S$ and relevant quality fields $Q I_{S}$ are taken.

Finally, the two fields are combined into the gaugeradar-satellite (GRS) precipitation field forming the final QPE by means of the weighting formula:

$$
G R S=\frac{G R \cdot Q I_{d}+G S \cdot\left(1-Q I_{d}\right) \cdot Q I_{S}}{Q I_{d}+\left(1-Q I_{d}\right) \cdot Q I_{S}}
$$

where the $Q I_{d}$ is the quality factor of radar data related to the distance to the nearest radar site.

The quality index field $Q I_{G R S}$ for the combined GRS precipitation is determined as a mean from particular $Q I_{G}$, $Q I_{R}$, and $Q I_{S}$ values with weights deduced from reliabilities of particular input fields.

\section{Nowcasting of the precipitation field (QPN) 4.1. General description}

Generally, nowcasting of precipitation can be described as a transformation of the precipitation field performed with its advection and physical evolution taken into account, according to the formula: 


$$
R\left(t_{0}+\Delta t, \mathbf{x}\right)=R\left(t_{0}, \mathbf{x}-\Delta \mathbf{x}\right)+\Delta R\left(t_{0}, \mathbf{x}-\Delta \mathbf{x}\right)
$$

where $R$ is the 10 -min precipitation accumulation; $t_{0}$ is the time when the nowcast is generated; $\Delta t$ is the nowcast lead time; $\mathbf{x}$ is the position of a given pixel; $\Delta \mathbf{x}$ is the change of the pixel position during the forecast lead time; $\Delta R$ is the change of the precipitation intensity (accumulation) encountered during the field evolution.

Extrapolation vectors $\Delta \mathbf{x}$ for nowcasting are determined by finding such movement between two subsequent QPE fields for which the correlation coefficient is the highest (Mecklenburg et al. 2005). This vector field is subject to quality control through either verification with neighbouring vectors or by using a variational technique with a continuity equation as a constraint ( $\mathrm{Li}$ et al. 1995).

Most often for the advection of a precipitation field a semi-Lagrangian backward scheme (e.g. Germann, Zawadzki 2002) is applied. In this scheme the field displacement is described for each pixel in a Lagrange space and the total movement vector $\Delta \mathbf{x}$ during time period $\Delta t$ is deduced from vectors for relevant time steps. The movement vectors differ between consecutive time steps as the individual vector is associated with a pixel shifted to a given location moving upstream in each time step, therefore this scheme allows for the changeability of vector field to be taken into account - e.g. due to rotation.

Simpler nowcasting models are focused only on the determination of the movement vectors, and neglect the evolution of the precipitation field $\Delta R$. However, at present more advanced models take this factor into consideration, which enables the lead time of forecasts to be lengthened without significant deterioration in terms of their reliability. The classic TITAN model (Dixon, Wiener 1993) employs a linear trend of evolution, while the GANDOLF model applies an empirical model of a convective cell lifecycle (Pierce et al. 2000). A similar approach is employed in the SCENE model that forms part of the SEiNO system - this introduces dedicated lifecycle models for different types of convective cells. A different concept is used in the STEPS model (Bowler et al. 2006), in which a secondorder autoregressive scheme AR is employed to generate forecasts. A similar solution is applied in the SNOF model currently also being developed within the frame of SEiNO.

\subsection{Nowcasting models in SEiNO}

INCA-PL2 is an adapted INCA (Integrated Nowcasting through Comprehensive Analysis) model of meteorological nowcasting developed by the Austrian national meteorological service ZAMG (Haiden et al. 2011; Kann et al. 2012). The Polish version, named INCA-PL, was developed in 2010-2013 within the frame of the European project INCA-CE (Interreg program). Since 2015 a version named INCA-PL2 has been operationally applied at IMGW-PIB. The model generates nowcasts of the main meteorological fields, including precipitation, type of precipitation, temperature, wind speed and direction, pressure, etc. In the case of precipitation it is an extrapolation model: nowcasts are obtained by advection defined by a movement vector field determined using a cross-correlation technique (Haiden et al. 2011).

SCENE (Storm Cell Evolution and Nowcasting) is a precipitation model developed at IMGW-PIB and optimized especially for convective events. It is an objectoriented model which contains the modules for: (i) the detection of convective precipitation based on meteorological information from weather radars, a Meteosat satellite, a lightning detection system and mesoscale NWP models, and also by applying fuzzy logic technique (Jurczyk et al. 2012), (ii) the division of the area into particular convective cells with the use of a geometrically-based approach, (iii) the determination of separate fields of movement vectors for stratiform precipitation and individual convection cells, (iv) the prediction of cell evolution by means of conceptual models for cell lifecycles developed for different precipitation structures.

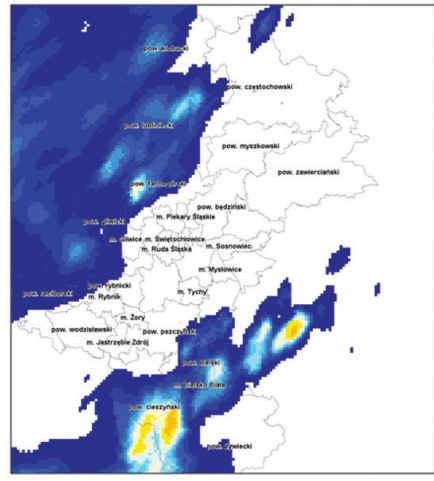

a) precipitation analysis from 19 UTC

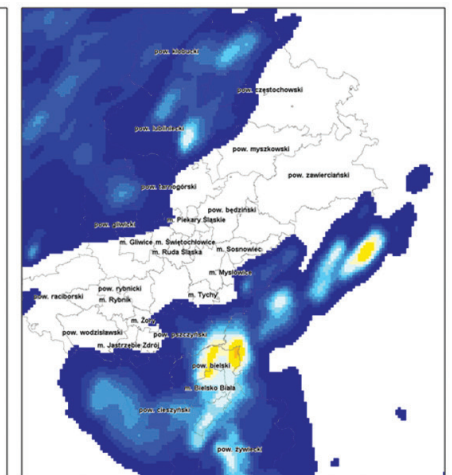

b) deterministic forecast for 20 UTC

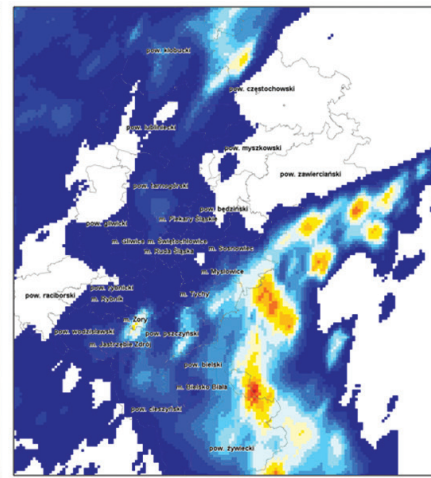

c) analysis from 20 UTC

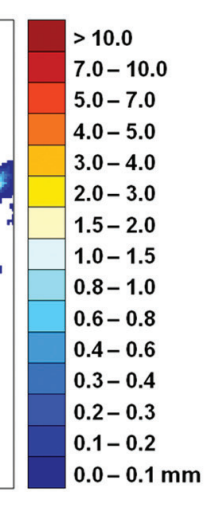

$1 \mathrm{~mm}$

Fig. 4. Example of nowcast generated by the SEiNO system on 12 July 2016 from 19 to 20 UTC: a) precipitation analysis from 19 UTC; b) deterministic nowcast for 20 UTC; c) precipitation analysis from 20 UTC which verifies the nowcast 
Table 1. Precipitation nowcasting models employed in the SEiNO system

\begin{tabular}{|l|l|l|l|}
\hline Characteristics of models & $\begin{array}{l}\text { INCA-PL2 } \\
\text { (precipitation module) }\end{array}$ & SCENE & SNOF \\
\hline Source of input data & RainGRS & RainGRS & RainGRS \\
\hline Auxiliary input data & NWP & $\begin{array}{l}\text { Radar network, Meteosat, NWP, lightning } \\
\text { detection system }\end{array}$ & No \\
\hline $\begin{array}{l}\text { Analysis of the precipita- } \\
\text { tion spatial structure }\end{array}$ & Not performed & $\begin{array}{l}\text { Detection of convection areas and } \\
\text { classification of precipitation structures }\end{array}$ & $\begin{array}{l}\text { Spectral analysis of precipitation field: } \\
\text { hydrometeor separation based on their } \\
\text { spatial scale }\end{array}$ \\
\hline Extrapolation idea & $\begin{array}{l}\text { Extrapolation of the } \\
\text { whole precipitation field }\end{array}$ & $\begin{array}{l}\text { Extrapolation using IMGW's algorithm with } \\
\text { object-oriented approach for convection area }\end{array}$ & $\begin{array}{l}\text { Extrapolation of particular layers related to } \\
\text { hydrometeor spatial scale using optical flow }\end{array}$ \\
\hline Precipitation evolution & Not considered & $\begin{array}{l}\text { Conceptual models of convective cell evolu- } \\
\text { tion for different precipitation structures }\end{array}$ & Autoregressive AR(2) model \\
\hline $\begin{array}{l}\text { State of advancement } \\
\text { (in February 2017) }\end{array}$ & Operational & In re-parameterisation & In test stage \\
\hline
\end{tabular}

The difference in terms of the determination of a movement vector field when compared to INCA group models is that the SCENE employs its own algorithm for quality control of the vectors by comparison with either a mean vector from a vicinity or a vector from a previous time step. Another important difference is that convective and stratiform precipitation are extrapolated separately.

SNOF (Spectral Nowcasting with Optical Flow) is a precipitation nowcasting model under development at the IMGW-PIB. The main property of the model is the separation of meteorological objects of different spatial scales with the use of 2D Fast Fourier Transformation, which divides a precipitation field into several layers. Each layer includes meteorological objects of similar scales which reflect different phenomena observed in the precipitation field, especially convective phenomena. In particular layers, the precipitation extrapolation is performed separately with movement vectors optimised by means of the optical flow technique. The field evolution is forecast separately in each layer, employing an autoregressive model of the second order AR(2) (Bowler et al. 2006). Finally, all the layers are aggregated into a nowcasted field. At present this model is in the testing stage.

\section{NWP forecasts}

At present, two groups of mesoscale NWP models are used operationally at IMGW-PIB. They are developed within the frame of participation in two international consortia: COSMO (COnsortium for Small-scale MOdelling) and ALADIN. The COSMO basic model and AROME model of the ALADIN system work in high-resolution configurations on a geographical mesh with a horizontal resolution of 2,8 km and 2,0 km, respectively. Both models are initialized four times per day at 00, 06, 12, and 18 UTC (Table 2).

Mesoscale NWP models often assimilate observation data, including weather radar data necessary to ensure the required horizontal resolution (Jakubiak et al. 2014). The tools implemented for the assimilation enable the application of data available every hour through the Global Telecommunications System and high frequency data provided by IMGW-PIB, e.g., every $10 \mathrm{~min}$ from weather radars and telemetric rain gauges. The assimilation in COSMO is based on a nudging scheme which corrects the initial conditions obtained from the global model with the measured data. The degree of the correction depends on the spatiotemporal distance between a specific measurement and a corrected value in the node of the computational mesh. Radar data are not yet assimilated into the AROME model.

The high-resolution NWP forecasts constitute a source of initial and boundary conditions for ultra short-term versions of these models, which currently generate forecasts every hour with a 10-min time step and spatial resolution of about $1-\mathrm{km}$ in research mode.

\section{Forecast processing}

\subsection{Forecast merging (MERGE)}

The generation of hybrid forecasts (QPF) by the MERGE module of the SEiNO system consists in blending two kinds of forecasts: (i) nowcasts (QPN) and

Table 2. High-resolution mesoscale NWP models working in the operational mode at IMGW-PIB

\begin{tabular}{|l|l|l|l|l|}
\hline Model & $\begin{array}{l}\text { Horizontal resolution } \\
{[\mathrm{km}]}\end{array}$ & Runs per day & Forecast range $[\mathrm{h}]$ & $\begin{array}{l}\text { Number of } \\
\text { ensemble members }\end{array}$ \\
\hline COSMO 2.8 & 2,8 & $4(00,06,12,18$ UTC) & 36 & 20 \\
\hline AROME & 2,0 & $4(00,06,12,18$ UTC $)$ & 30 & 52 \\
\hline
\end{tabular}




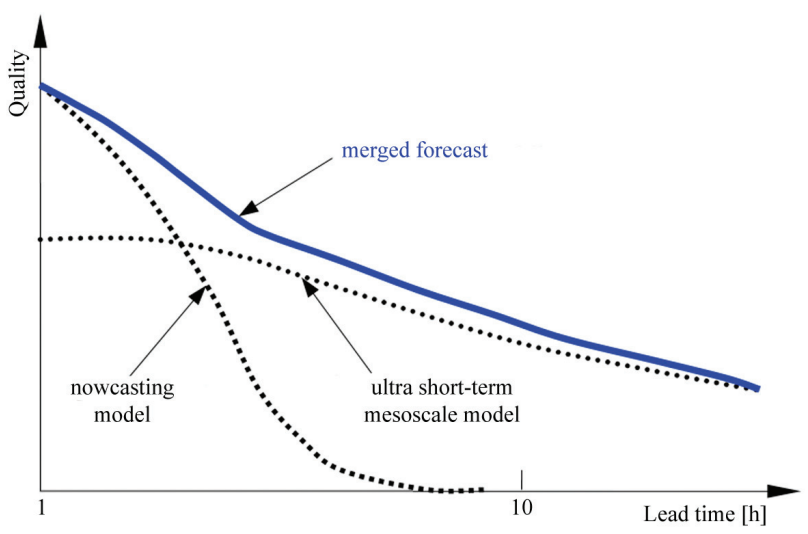

Fig. 5. Schematic diagram of reliability of nowcasts and ultra short-term forecasts for different lead times (based on Golding 1998)

(ii) ultra short-term forecasts produced by high-resolution versions of mesoscale NWP models. The forecasts are generated by means of various prediction algorithms and complement each other, so the merging algorithm is based on an idea that particular methodologies are characterized by different reliabilities in different lead times, as depicted in Fig. 5.

The merging is based on analysis of forecast reliability for a certain number of previous time steps in order to determine the merged forecast as a weighted mean with proper weighting. For this purpose, some statistical reliability metrics are calculated in real time by means of a METRICS module. A certain set of criteria values, both continuous and based on a contingency table (Gilleland et al. 2010) determined by the METRICS for the last (e.g., 24 time steps) is taken to calculate the weight of the data $W_{i}(t)$ for a given lead time $t$. The weight is modified by factor $W_{i}^{\text {mod }}(t)$, which depends on the forecasting model and the lead time. Finally, the weighted forecast $F(t)$ is computed from individual model forecasts $F_{i}(t)$ using the following formula:

$$
F(t)=\frac{\sum_{i}\left(W_{i}(t) \cdot W_{i}^{\bmod }(t) \cdot F_{i}(t)\right)}{\sum_{i}\left(W_{i}(t) \cdot W_{i}^{\bmod }(t)\right)}
$$

The quality field assigned to the merged forecast is computed from the formula:

$$
Q I_{\text {output }}(t)=\frac{\sum_{i}\left(W_{i}(t) \cdot W_{i}^{\text {mod }}(t) \cdot Q I_{i}(t)\right)}{\sum_{i}\left(W_{i}(t) \cdot W_{i}^{\text {mod }}(t)\right)}
$$

The MERGE module is employed in the three stages of forecast processing to merge all nowcasts and NWP ultra short-term forecasts separately and finally to combine the two merged forecasts into one set of hybrid forecasts.

\subsection{Producing probabilistic forecasts (ENSEMBLE, PROB)}

In recent years many efforts have been made that aim at developing the methodology for the generation of probabilistic forecasts because they provide more comprehensive information about predicted phenomena, particularly about their uncertainty. The approach used in the SEiNO system is based on the general idea that a nowcast of precipitation in a given pixel is modified by adding a certain set of perturbations related to the data quality in this pixel. The perturbations are to generate an ensemble of equiprobable nowcasts:

$$
R_{i}\left(t_{0}+\Delta t, \mathbf{x}\right)=R\left(t_{0}+\Delta t, \mathbf{x}\right)+\delta_{i}\left(t_{0}+\Delta t, \mathbf{x}\right)
$$

where: $R_{i}$ is the 10 -min precipitation accumulation in $i$-th member of a precipitation ensemble; $R$ is the deterministic precipitation (rate or accumulation); $\delta_{i}$ is the perturbation introduced into precipitation in $i$-th member of the ensemble.

Perturbation fields $\delta_{i}$ are generated by a technique based on the data quality introducing a random factor. As a starting point, an error covariance matrix $\mathbf{A}$ of a precipitation field is determined. Germann et al. (2009) compute the matrix statistically by comparison of the radar and rain gauge measurements with historical data and then decompose it into a triangular $\mathbf{L}$ matrix, applying a Cholesky technique. In the PROB module of the SEiNO system, the matrix $\mathbf{A}$ is dynamically calculated by an adaptive method in which, contrary to the static approach of Germann, the error covariance matrix of an estimated precipitation field is determined on the basis of current precipitation $R$ and $Q I$ values. This allows the impact of current measurement errors in input data to be taken into account, which is especially crucial in the case of radar measurements due to the extremely changeable characteristics of their errors over time (see Sect. 2.3).

A particular $i$-th perturbation vector is generated by the multiplication of the $\mathbf{L}$ matrix by $i$-th vector of white noise $\varepsilon_{\mathrm{i}}$ :

$$
\delta_{i}(t)=\mathbf{L}(t) \cdot \varepsilon_{i}
$$

Applying these perturbation vectors to Equation 7, an ensemble of nowcasts is generated from deterministic nowcasts $R$ in the form of a package of $n$ equiprobable precipitation scenarios and its spread is determined by the L matrix. Such nowcast ensembles may consist of a different number of members, but for ensemble prediction systems implemented in mesoscale NWP models the number between 20 to 50 members is suggested (Roulin, Vannitsem 2005; Eckel, Delle Monache 2016). 


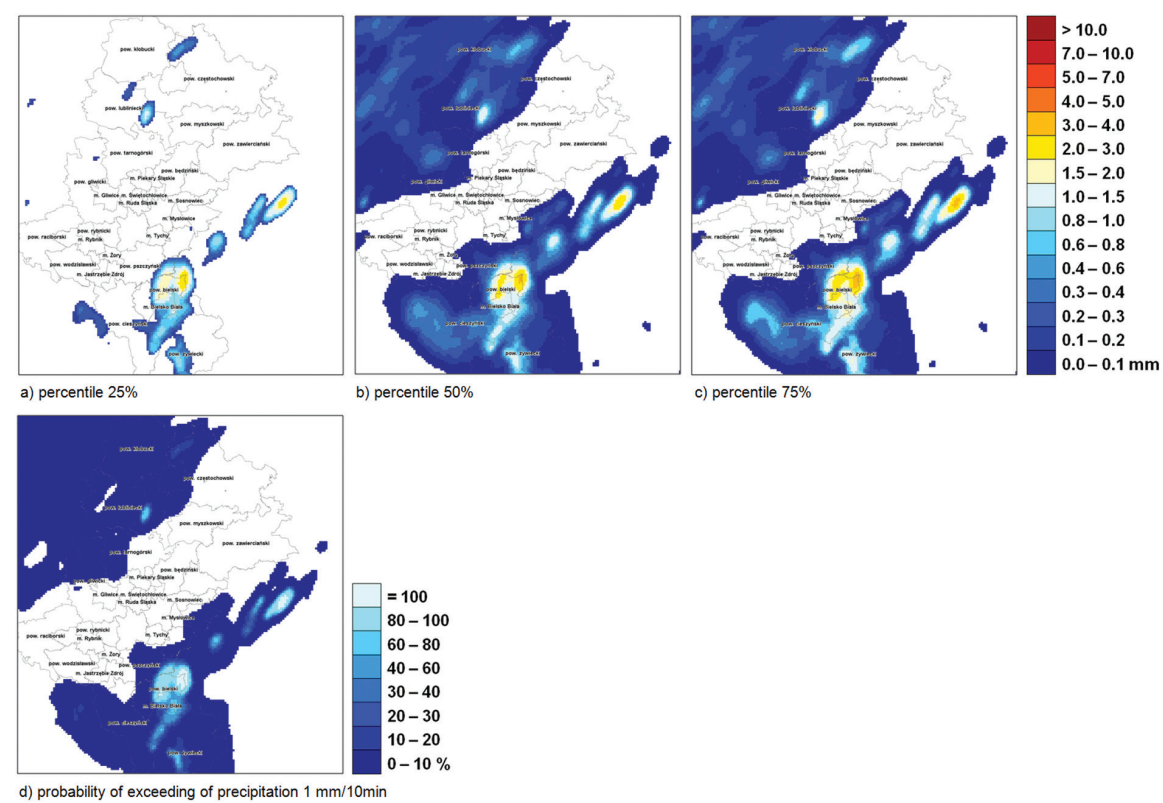

Fig. 6. Example of probabilistic nowcast generated by the SEiNO system on 12 July 2016 from 19 to 20 UTC: a-c) percentiles of precipitation PDF $25 \%, 50 \%$, and $75 \%$; d) spatial distribution of probability of exceeding $1 \mathrm{~mm} 10 \mathrm{~min}^{-1}$ precipitation

Working with the ensembles may be inconvenient, so they are processed to deliver more synthetic information expressed by the probability density function (PDF). For this purpose, the appropriate PDF describing the precipitation must be assumed; a gamma PDF is most often chosen because of its shape, which corresponds to the empirically obtained histograms. The PDF parameters are estimated from the precipitation values in all ensemble members for each pixel separately (Szturc et al. 2008, 2010). Then, based on the parameterized PDF, the nowcasts can be presented in one of the two proposed forms: (i) as a set of percentiles of the probability distribution (e.g. 5, 25, 50,75 , and $95 \%$ ); (ii) by the probability of exceedance of a preset precipitation threshold (e.g. 1 or $10 \mathrm{~mm} \mathrm{~h}^{-1}$ ).

In figure 6 shows an example of the probabilistic forecasts generated for the example from Fig. 4. For the deterministic nowcast (Fig. $4 \mathrm{~b}$ ) the probabilistic forecasts in the form of PDF percentiles (Fig. 6a-c) and probability of precipitation exceeding $1 \mathrm{~mm} 10 \mathrm{~min}^{-1}$ (Fig. 6d) are presented.

\section{Summary}

The SEiNO system consists of a set of applications and modules for precipitation data processing, and the estimation and nowcasting of a precipitation field. Most of the developed algorithms are based on the use of quality information generated quantitatively at each stage of the data processing. Moreover, the generation of probabilistic data presented in the form of sets of percentiles or probabilities of exceedance is introduced.
The most important properties of the SEiNO system are: (i) the high spatial and temporal resolution $(1 \mathrm{~km}$ and $10 \mathrm{~min}$, respectively), (ii) a multi-model approach which allows the system - by the selection of one algorithm from different alternative ones for each individual task - to be configured, especially in the case of nowcasting, (iii) the crucial role of data quality at each stage of the data processing, (iv) the taking into account of the real-time reliability of generated nowcasts.

Some of the SEiNO modules have been running operationally at IMGW-PIB for a few years. They have proven to work effectively and on a satisfactory level, especially the RainGRS module and related applications for quality control of input data. When it comes to other modules, it is necessary to work on their reliability; for example, the SCENE needs improvements in terms of more advanced algorithms, such as object-oriented extrapolation and modeling of convective precipitation evolution. Newer modules, like those for the generation of probabilistic precipitation (PROB), require the development of methodology for the validation of their outputs; on top of this, the employed algorithms are too time-consuming. More innovative modules like SNOF are still under development.

\section{Acknowledgements}

The authors greatly appreciate the significant input from numerous colleagues at IMGW-PIB towards building the SEiNO system. We especially wish to express our gratitude to Dr. Irena Otop, Dr. Piotr Struzik, Mateusz Giszterowicz and Paweł Przeniczny. 


\section{List of abbreviations}

ANSI C - standard for the C programming language

AR - autoregressive model

ALADIN - NWP consortium

AROME - NWP model of the ALADIN consortium

CentOS - Community Enterprise Operating System (distribution of Linux operating system)

COSMO - Consortium for small-scale modelling (NWP consortium)

EUMETNET - network of European national meteorological services

GANDOLF - Generating Advanced Nowcasts for Deployment in Operational Land-based Flood Forecasts HDF5 - Hierarchical Data Format 5 (file format)

IMGW-PIB - Institute of Meteorology and Water Management - National Research Institute (in Polish: Instytut Meteorologii i Gospodarki Wodnej - Państwowy Instytut Badawczy) (Polish national meteorological service)

INCA - Integrated Nowcasting through Comprehensive Analysis (nowcasting model)

INCA-CE - INCA Central Europe (European project)

INCA-PL - INCA model adapted by IMGW-PIB

INCA-PL2 - INCA model adapted by IMGW-PIB, v. 2

MERGE - SEiNO module for the merging of precipitation data

METRICS - SEiNO module for the generation of reliability statistics for precipitation data

NWC SAF - Satellite Application Facility on Support to Nowcasting and Very Short Range Forecasting (EUMETSAT program)

NWP - numerical weather prediction

ODIM - OPERA digital information model

OPERA - Operational Programme for the Exchange of Weather Radar Information (EUMETNET program)

PAC - precipitation accumulation (radar product)

PDF - probability density function

POLRAD - Polish weather radar network

PQPF - probabilistic QPF

PROB - SEiNO module for the generation of probabilistic forecasts

PUWG 92 - Polish coordinate system (Państwowy Układ Współrzędnych Geodezyjnych 1992)

QPE - quantitative precipitation estimate

QPF - quantitative precipitation forecast

QPN - quantitative precipitation nowcast

RADVOL-QC - System of weather radar 3D data quality control

RainGRS - SEiNO module for multi-source QPE

RLAN - Radio Local Area Network

SCENE - Storm Cell Evolution and Nowcasting (nowcasting model)
SEiNO - System for the Estimation and Nowcasting of Precipitation (in Polish: System Estymacji i Nowcastingu Opadów)

Selex ES - weather radar manufacturer

SEVIRI - Spinning Enhanced Visible and Infrared Imager (Meteosat radiometer)

SNOF - Spectral Nowcasting with Optical Flow (nowcasting model)

SRI - surface rainfall intensity (radar product)

STEPS - Short Term Ensemble Prediction System (nowcasting model)

TITAN - Thunderstorm Identification Tracking Analysis and Nowcasting (nowcasting model)

SUM - SEiNO module for precipitation accumulation ZAMG - Zentralanstalt für Meteorologie und Geodynamik (Austrian national meteorological service)

\section{Bibliography}

Atencia A., Rigo T., Sairouni A., Moré J., Bech J., Vilaclara E., Cunillera J., Llasat M.C. Garrote, L., 2010, Improving QPF by blending techniques at the Meteorological Service of Catalonia, Natural Hazards and Earth System Sciences, 10, 1443-1455, DOI: 10.5194/nhess-10-1443-2010

Berndt C., Rabiei E., Haberlandt U., 2014, Geostatistical merging of rain gauge and radar data for high temporal resolutions and various station density scenarios, Journal of Hydrology, 508, 88-101, DOI: 10.1016/j.jhydrol.2013.10.028

Bowler N.E., Pierce C E., Seed A.W., 2006, STEPS: A probabilistic precipitation forecasting scheme which merges an extrapolation nowcast with downscaled NWP, Quarterly Journal of the Royal Meteorological Society, 132 (620), 2127-2155, DOI: 10.1256/qj.04.100

Dixon M., Wiener G., 1993, TITAN: thunderstorm identification, analysis, and nowcasting - A radar-based methodology, Journal of Atmospheric and Oceanic Technology, 10 (6), 785-797, DOI: 10.1175/1520-0426(1993)010<0785:TTITA $\mathrm{A}>2.0 . \mathrm{CO} ; 2$

Eckel F.A., Delle Monache L., 2016, A hybrid NWP-analog ensemble, Monthly Weather Review, 144, 897-911, DOI: 10.1175/MWR-D-15-0096.1

Einfalt T., Szturc J., Ośródka K., 2010, The quality index for radar precipitation data: a tower of Babel?, Atmospheric Science Letters, 11 (2), 139-144, DOI: 10.1002/asl.271

Germann U., Berenguer M., Sempere-Torres D., Zappa M., 2009, REAL - Ensemble radar precipitation estimation for hydrology in a mountainous region, Quarterly Journal of the Royal Meteorological Society, 135 (639), 445-456, DOI: 10.1002/qj.375

Germann U., Zawadzki I., 2002, Scale-dependence of the predictability of precipitation from continental 
radar images. Part I: Description of the methodology, Monthly Weather Review, 130, 2859-2873, DOI: 10.1175/1520-0493(2002)130<2859:SDOTPO >2.0.CO;2

Gilleland E., Ahijevych A.A., Brown B.G., Ebert E.E., 2010, Verifying forecasts spatially, Bulletin of the American Meteorological Society, 91, 1365-1373, DOI: 10.1175/2010BAMS2819.1

Golding B.W., 1998, Nimrod: A system for generating automated very short range forecasts, Meteorological Applications, 5 (1), 1-16, DOI: 10.1017/S1350482798000577

Haiden T., Kann A., Wittmann C., Pistotnik G., Bica B., Gruber C., 2011, The Integrated Nowcasting through Comprehensive Analysis (INCA) system and its validation over the Eastern Alpine Region, Weather and Forecasting, 26, 166-183, DOI: 10.1175/2010WAF2222451.1

Jakubiak B., Szturc J., Ośródka K., Jurczyk A., 2014, Experiments with three-dimensional radar reflectivity data assimilation into the COAMPS model, Meteorology Hydrology and Water Management. Research and Operational Applications, 2 (1), 43-54, DOI: 10.26491/mhwm/28893

Jurczyk A., Ośródka K., Szturc J., 2012, Convective cell identification using multi-source data, IAHS Publications, 351, 360-366

Kann A., Pistotnik G., Bica B., 2012, INCA-CE: a Central European initiative in nowcasting severe weather and its applications, Advances in Science and Research, 8, 67-75, DOI: 10.5194/asr-8-67-2012

Mecklenburg, S., Jurczyk, A., Szturc, J., Ośródka, K., 2005, Use of radar observation in hydrological and NWP models. Quantitative precipitation forecasts (QPF) based on radar data for hydrological models, COST Action 717, Luxembourg, 36 pp.

Michelson D.B., Lewandowski R., Szewczykowski M., Beekhuis H., Haase G., 2014, EUMETNET OPERA weather radar information model for implementation with the HDF5 file format. Version 2.2, EUMETNET OPERA Document, 38 pp., available at http://eumetnet.eu/wp-content/uploads/2017/01/ OPERA_hdf_description_2014.pdf(data access 22.08.2017)

NWC SAF, 2013, NWCSAF/MSG Basic Documents, v2013, EUMETSAT NWC SAF Program, available at http://www. nwcsaf.org/indexScientificDocumentation.html (data access 22.08.2017)

Ośródka K., Szturc J., Jurczyk A., 2014, Chain of data quality algorithms for 3-D single-polarization radar reflectivity (RADVOL-QC system), Meteorological Applications, 21 (2), 256-270, DOI: 10.1002/met.1323

Pierce C.E., Hardaker P.J., Collier C.G., Haggett C.M., 2000, GANDOLF: a system for generating automated nowcasts of convective precipitation, Meteorological Applications, 7 (4), 341-360, DOI: 10.1017/S135048270000164X

Pierce C., Seed A., Ballard S., Simonin D., Li Z., 2012, Nowcasting, [in:] Doppler radar observations - weather radar, wind profiler, ionospheric radar, and other advanced applications, J. Bech, J.L. Chau (eds.), InTech, Rijeka, 97-142

Roulin E., Vannitsem S., 2005, Skill of medium-range hydrological ensemble predictions, Journal of Hydrometeorology, 6, 729-744, DOI: 10.1175/JHM436.1

Silvestro F., Rebora N., Cummings G., Ferraris L., 2015, Experiences of dealing with flash floods using an ensemble hydrological nowcasting chain: implications of communication, accessibility and distribution of the results, Journal of Flood Risk Management (early view), DOI: 10.1111/jfr3.12161

Sinclair S., Pegram G., 2005, Combining radar and rain gauge rainfall estimates using conditional merging, Atmospheric Science Letters, 6 (1), 19-22, DOI: 10.1002/asl.85

Szturc J., Jurczyk A., Ośródka K., Struzik P., Otop I., 2014, Estimation of a surface precipitation field based on multisource data and quality information, (in Polish), Monografie Komitetu Gospodarki Wodnej PAN, 20 (2), 19-30

Szturc J., Ośródka K., Einfalt T., Jurczyk A., 2010, Rainfall and runoff ensembles based on the quality index of radar precipitation data, [in:] Advances in radar applications, Proceedings of the 6th European Conference on Radar in Meteorology and Hydrology. ERAD, Sibiu, Romania, 446-452

Szturc J., Ośródka K., Jurczyk A., Jelonek L., 2008, Concept of dealing with uncertainty in radar-based data for hydrological purpose, Natural Hazards and Earth System Sciences, $8,267-279$

Ten Veldhuis J.A.E., Ochoa-Rodriguez S., Bruni B., Gires A., van Assel J., Wang L., Reinoso-Rodinel R., Kroll S., Schertzer D., Onof C. Willems P., 2014, Weather radar for urban hydrological applications: lessons learnt and research needs identified from 4 pilot catchments in North-West Europe, [in:] Proceedings of the International Symposium Weather Radar and Hydrology, Washington, April 7-10

Tokarczyk T., Szalińska W., Tiukało A., Jełowicki J., Chorążyczewski A., 2016, Computational environment HYDRO-PATH as a flexible tool for operational rainfallrunoff model design, Meteorology Hydrology and Water Management. Research and Operational Applications, 4 (1), 65-77, DOI: $10.26491 / \mathrm{mhwm} / 63366$

Villarini G., Krajewski W.F., 2010, Review of the different sources of uncertainty in single polarization radar-based estimates of rainfall, Surveys in Geophysics, 31 (1), 107-129, DOI: 10.1007/s10712-009-9079-x 